\title{
Simulação computadorizada do perfil facial em cirurgia ortognática: precisão cefalométrica e avaliação por ortodontistas
}

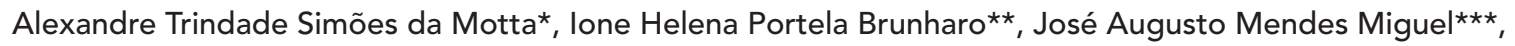
Jonas Capelli Jr. ${ }^{\star \star \star}$, Paulo José D’Albuquerque Medeiros ${ }^{\star \star \star \star}$, Marco Antonio de Oliveira Almeida

\begin{abstract}
Resumo
Objetivo: verificar a precisão de um programa de simulação computadorizada na predição de alterações no perfil facial em diferentes tipos de cirurgia ortognática. Metodologia: utilizou-se radiografias e fotografias de perfil das fases pré-cirúrgica e final de 32 pacientes. As movimentações esqueléticas do procedimento cirúrgico foram reproduzidas no traçado pré-cirúrgico, gerando mudanças no perfil mole, originando o traçado e a imagem predictiva de perfil. Analisou-se o perfil da amostra total e dividida em dois grupos, sem cirurgias no sentido vertical (AP) e com cirurgias de impacção ou reposicionamento inferior da maxila (V). Comparou-se cefalometricamente pontos do perfil mole dos traçados predictivo e final. As imagens predictivas computadorizadas foram comparadas com as imagens finais por 20 ortodontistas, que avaliaram cinco regiões: perfil total, nariz, lábio superior, lábio inferior e mento. Resultados e Conclusões: observou-se variabilidade de posicionamento dos pontos do perfil, com mais de $60 \%$ dos erros até $2 \mathrm{~mm}$ e $17 \%$ acima de $3 \mathrm{~mm}$. Diferenças significativas entre os pontos foram mais freqüentes no sentido vertical. Os ângulos nasolabial e mentolabial predictivos apresentaram-se mais agudos que os finais. As notas médias encontradas na análise subjetiva variaram de 56 para o lábio inferior a 75,42 para o nariz. As imagens predictivas não apresentaram diferenças significativas de qualidade entre os grupos. Em comparação com outros sistemas de simulação computadorizada, este programa pode ser considerado útil na prática clínica ortodôntica e cirúrgica. Entretanto, diante de algumas limitações observadas, recomenda-se cautela no planejamento e apresentação do caso, considerando que algumas predições podem exigir melhorias com ferramentas de ajuste.
\end{abstract}

Palavras-chave: Simulação computadorizada. Predição do perfil. Cirurgia ortognática.

* Doutor, Mestre e Especialista em Ortodontia (Universidade do Estado do Rio de Janeiro - UERJ). Professor Assistente de Ortodontia (Univer-

sidade Estácio de Sá - UNESA).

** Doutora, Mestre e Especialista em Ortodontia (UERJ).

*** Professor Adjunto de Ortodontia (UERJ).

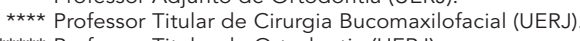

***** Professor Titular de Ortodontia (UERJ). 


\section{INTRODUÇÃO}

$\mathrm{O}$ tratamento ortodôntico associado à cirurgia ortognática constitui-se em um dos procedimentos com maiores chances de melhoria estética na Odontologia. Apesar da importância da correção de problemas funcionais, é marcante a preocupação de ortodontistas, cirurgiões e pacientes em relação às modificações faciais pós-cirúrgicas. Isto fez com que se buscassem métodos capazes de prever e visualizar a forma e o posicionamento das estruturas moles da face, principalmente nariz, lábios e mento, após procedimentos cirúrgicos ${ }^{11,12,14,15,17}$.

Basicamente, a predição do resultado estético em cirurgia ortognática vem sendo realizada de três formas. A primeira, mais antiga e ainda utilizada, baseia-se na realização do traçado cefalométrico predictivo de forma manual em papel acetato. A segunda alternativa permite que os movimentos cirúrgicos sejam realizados em computador, proporcionando traçados cefalométricos com diferentes opções de tratamento. $\mathrm{Na}$ terceira opção, simulações computadorizadas são obtidas unindo-se o traçado cefalométrico à imagem fotográfica de perfil, que sofre alterações de acordo com as mudanças nos tecidos duros. Este último método, conhecido também como video imaging, apresenta algumas vantagens descritas na literatura ${ }^{1,2,4,6,8,13,19,20}$, como melhorias na visualização e no entendimento dos objetivos do tratamento pelo paciente. O apelo visual da simulação computadorizada pode suprir as deficiências do profissional na apresentação do caso ao paciente, que antes era realizada com o auxílio de traçados cefalométricos, modelos de estudo e fotografias de outros pacientes tratados, de difícil entendimento para um leigo ${ }^{5,16}$. Além disso, a possibilidade de se realizar planejamentos ortocirúrgicos com maior facilidade e precisão tornou este método mais utilizado e estudado nos últimos dez anos.

Apesar de algumas diferenças descritas na literatura acerca dos diversos programas já testados, semelhanças básicas podem ser notadas. Defici- ências na predição do lábio inferior, variabilidade no posicionamento de alguns pontos do perfil mole predictivo e produção de imagens com algumas falhas visuais foram relatadas em praticamente todos os experimentos com o Dentofacial Planner (DFP) 3 3,4,22, Dolphin Imaging (DI) ${ }^{10,22}$, Orthognathic Treatment Planner (OTP) 2,18,22,23, Prescription Planner Portrait (PPP) ${ }^{8,13,18,21,23}$, Quick Ceph Image (QCI) ${ }^{6,8,22,24}$ e Vistadent ${ }^{22}$. Cinco programas (DFP, DI, Orthoplan, QCI e Vistadent) foram comparados na predição de $10 \mathrm{ca}$ sos considerados difíceis, utilizando seus recursos de retoque das imagens, com o DFP mostrando um melhor desempenho, seguido pelo DI e QCI. Contudo, fatores como facilidade de uso, custo, compatibilidade com sistemas operacionais e suporte técnico devem ser considerados na escolha de um software ${ }^{22}$.

$\mathrm{Na}$ verdade, os possíveis benefícios oferecidos por este método estão diretamente relacionados à precisão das imagens obtidas. Os fabricantes exibem novas versões, tentando corrigir falhas ou limitações de produtos anteriores, o que destaca a importância da realização de novos experimentos envolvendo os mais diversos tipos de tratamentos ortocirúrgicos.

O propósito deste trabalho foi verificar a precisão de um programa de simulação computadorizada na predição de mudanças ocorridas no perfil mole de pacientes submetidos a diferentes tipos de cirurgia ortognática.

\section{MATERIAL E MÉTODOS Seleção da amostra}

De um total de 129 documentações ortodônticas de pacientes submetidos a tratamento ortocirúrgico, foram selecionadas radiografias cefalométricas laterais e fotografias (slides) de perfil das fases pré-cirúrgica e final de 32 pacientes ( 24 do gênero feminino e 8 do gênero masculino), com média de idades de 23,6 anos (variação de 16 anos e 3 meses a 40 anos e 1 mês) no momento da cirurgia. A amostra foi colhida no arquivo 
da Clínica de Ortodontia da Universidade do Estado do Rio de Janeiro (UERJ) e do consultório particular de três ortodontistas e de um cirurgião bucomaxilofacial vinculados à instituição. Cinco casos foram gentilmente cedidos pelo Programa de pós-graduação em Ortodontia da UFRJ.

O quadro 1 exibe a divisão da amostra e o número de casos por procedimento cirúrgico. Os seguintes critérios foram utilizados para a seleção da amostra: (1) os pacientes não apresentavam mais crescimento ósseo na época da cirurgia ortognática; (2) as tomadas cefalométricas haviam sido feitas com os lábios em repouso e com os dentes em oclusão cêntrica; (3) as fotografias foram consideradas livres de distorções ou variações grosseiras na posição da cabeça, proporcionando uma vista real do perfil; (4) a documentação final havia sido realizada pelo menos 6 meses após a cirurgia, minimizando possíveis efeitos do edema pós-operatório na precisão das imagens; (5) as radiografias e fotografias finais haviam sido realizadas após a remoção do aparelho ortodôntico, evitando alterações na postura labial; (6) a fase ortodôntica pós-cirúrgica havia consistido em dobras de finalização e mecânica de elásticos, sem influência significante no perfil facial e (7) não foram utilizados pacientes portadores de deformidades congênitas ou fissuras labiopalatais.

\begin{tabular}{cc}
\hline procedimento cirúrgico & n \\
\hline recuo mandibular* & 10 \\
avanço mandibular* & 3 \\
avanço maxilar + recuo mandibular & 2 \\
impacção e avanço maxilar + recuo mandibular* & 6 \\
impacção maxilar + recuo mandibular + mentoplastia & 2 \\
impacção maxilar + avanço mandibular* & 5 \\
impacção maxilar* & 3 \\
reposição inferior de maxila + avanço mandibular & 1 \\
\hline
\end{tabular}

* Com ou sem mentoplastia.

Quadro 1 - Descrição dos tipos de procedimentos cirúrgicos a que haviam sido submetidos os pacientes da amostra.
As radiografias e fotografias pré-cirúrgicas haviam sido realizadas com uma média de 32,6 dias (variação: 15 a 45 dias) e 36,8 dias (15 a 45 dias) antes da cirurgia, respectivamente. As radiografias e fotografias finais haviam sido realizadas com uma média de 12,3 meses ( 6 a 26 meses) e 13,0 meses (6 a 26 meses) após a cirurgia, respectivamente. O tempo médio entre as documentações pré-cirúrgica e final foi de 14,7 meses $(7,5$ a 29 meses) e 15,2 meses (7,5 a 30 meses), respectivamente. $\mathrm{O}$ experimento foi submetido e aprovado pelo comitê de ética da instituição.

\section{Método de predição}

Testou-se o programa de cefalometria computadorizada e planejamento ortodôntico e cirúrgico Vistadent AT 2.1 (GAC Intl./ nº de série: V011201). O computador (AMD K7 Duron $1000 \mathrm{MHz}, 256 \mathrm{Mb}$ RAM, 40 Gb HD), o monitor (Samsung Syncmaster $3 \mathrm{Ne}$ ) e a impressora (HP Deskjet 3320) utilizados atendiam à configuração mínima exigida no manual do programa. Uma câmera digital (Nikon Coolpix 4500) e um duplicador de slides (Nikon ES-E28) foram utilizados na digitalização das imagens, editadas com o programa Corel Photo-Paint Select Edition (Corel Corporation - $\mathrm{n}^{\circ}$ de série: D70-17655U9448). No intuito de aprimorar e padronizar a qualidade das imagens para o experimento, estas foram giradas, redimensionadas e recortadas, além de receberem ajustes de cor, brilho e contraste, porém sem alterar seu conteúdo e suas proporções.

O programa Vistadent AT 2.1 gera um traçado predictivo do perfil mole a partir de alterações efetuadas na posição dos tecidos duros da face. Tais mudanças seguem valores baseados em dados da literatura, conhecidos como proporções ou razões de alteração entre tecidos duros e tecidos moles, que podem ser modificados no programa. Neste experimento, com o intuito de evitar variáveis adicionais, foram seguidos os valores fornecidos pelo fabricante, expressos no quadro 2 . 
Simulação computadorizada do perfil facial em cirurgia ortognática: precisão cefalométrica e avaliação por ortodontistas

\begin{tabular}{|c|c|c|c|c|}
\hline \multirow{2}{*}{ ponto } & \multicolumn{2}{|c|}{ esquelético } & \multicolumn{2}{|c|}{ dentário } \\
\hline & $\mathbf{x}$ & $y$ & $\mathbf{x}$ & $y$ \\
\hline \multicolumn{5}{|c|}{ maxila } \\
\hline pronasal & 1,00 & 0,15 & & \\
\hline subnasal & 0,24 & 0,28 & & \\
\hline ponto $A^{\prime}$ & 0,20 & 0,20 & 0,52 & 0,26 \\
\hline lábio superior & 0,62 & 0,31 & & \\
\hline estômio superior & 0,62 & 0,25 & & \\
\hline $\begin{array}{l}\text { ponto da linha do } \\
\text { estômio }\end{array}$ & 0,62 & 0,20 & & \\
\hline \multicolumn{5}{|c|}{ mandíbula } \\
\hline estômio inferior & 1,00 & 0,10 & 0,40 & 1,00 \\
\hline lábio inferior & 1,00 & 0,10 & 0,70 & 1,00 \\
\hline ponto $B^{\prime}$ & 1,00 & 1,00 & & \\
\hline pogônio mole & 1,00 & 1,00 & & \\
\hline gnátio mole & 1,00 & 1,00 & & \\
\hline mento mole & 1,00 & 1,00 & & \\
\hline ponto cervical & 0,20 & 0,40 & & \\
\hline
\end{tabular}

Quadro 2 - Razões de alteração entre tecidos duros e moles para os pontos do perfil, fornecidos pelo fabricante, para o eixo $X$ (horizontal) e $Y$ (vertical). Os valores indicam a proporção de alteração do tecido mole resultante do movimento esquelético ou dentário (Fonte: Vistadent AT 2.1, GAC International Inc.)

Foi realizada na tela do computador, em cada radiografia da amostra, a marcação dos pontos cefalométricos pré-estabelecidos pelo programa para a delimitação automática das estruturas anatômicas. $\mathrm{O}$ passo seguinte foi o acoplamento do traçado à fotografia de perfil correspondente. Ferramentas de ajuste possibilitam que o traçado seja manipulado até um alinhamento adequado, tendo como referência a linha do perfil mole fotográfico. No recurso de calibração, marcou-se a linha Sela-Násio na radiografia digital e informou-se ao programa seu comprimento real na película radiográfica, estabelecendo-se uma escala dimensional.

Utilizando-se a função de planejamento cirúrgico, foi feita a simulação do tratamento, repetindo-se no traçado predictivo as alterações esqueléticas promovidas pela cirurgia ortognática. Tais alterações foram verificadas em quantidade e direção por meio de superposição em Sela-Násio entre os traçados final e pré-cirúrgico. Assim, o traçado final funcionou como um template para a manipulação dos tecidos duros no traçado predictivo, de forma que estes puderam ser movidos nos planos horizontal e vertical, girados e inclinados até que atingissem sua posição final. Após a reprodução exata do procedimento cirúrgico, automaticamente ocorreram alterações no perfil mole, originando a imagem predictiva computadorizada (Fig. 1).

\section{Análise do perfil}

A precisão da predição foi avaliada sob dois aspectos: 1) comparando-se a localização cefalométrica de pontos selecionados do perfil mole nos traçados predictivo e final (análise cefalométrica) e 2) comparando-se a semelhança estética entre o perfil das imagens predictiva e final (análise subjetiva). A amostra foi analisada como um todo e dividida em dois grupos: AP ( $n=15)$, com indivíduos submetidos a cirurgias apenas no sentido ântero-posterior, e V ( $\mathrm{n}=17)$, envolvendo cirurgias de impacção ou reposição inferior de maxila.

Para a análise cefalométrica (Fig. 2), os traçados predictivo e final com seus respectivos pontos do perfil mole marcados foram superpostos em Sela-Násio. A imagem da superposição foi analisada através de um sistema de réguas perpendiculares, calibradas em milímetros, que permitia posicionar o mouse sobre qualquer ponto cefalométrico do perfil e verificar seu posicionamento nos eixos horizontal e vertical. Em seguida, calculou-se a diferença de cada ponto do traçado predictivo, pelo ponto correspondente no traçado final. Padronizou-se, portanto, que diferenças com valores negativos indicariam um ponto predictivo mais retruído no sentido horizontal e mais superior em relação ao ponto final no sentido vertical. Valores positivos indicariam um ponto predictivo mais protruído e inferior. Calculou-se diferenças entre os ângulos nasola- 

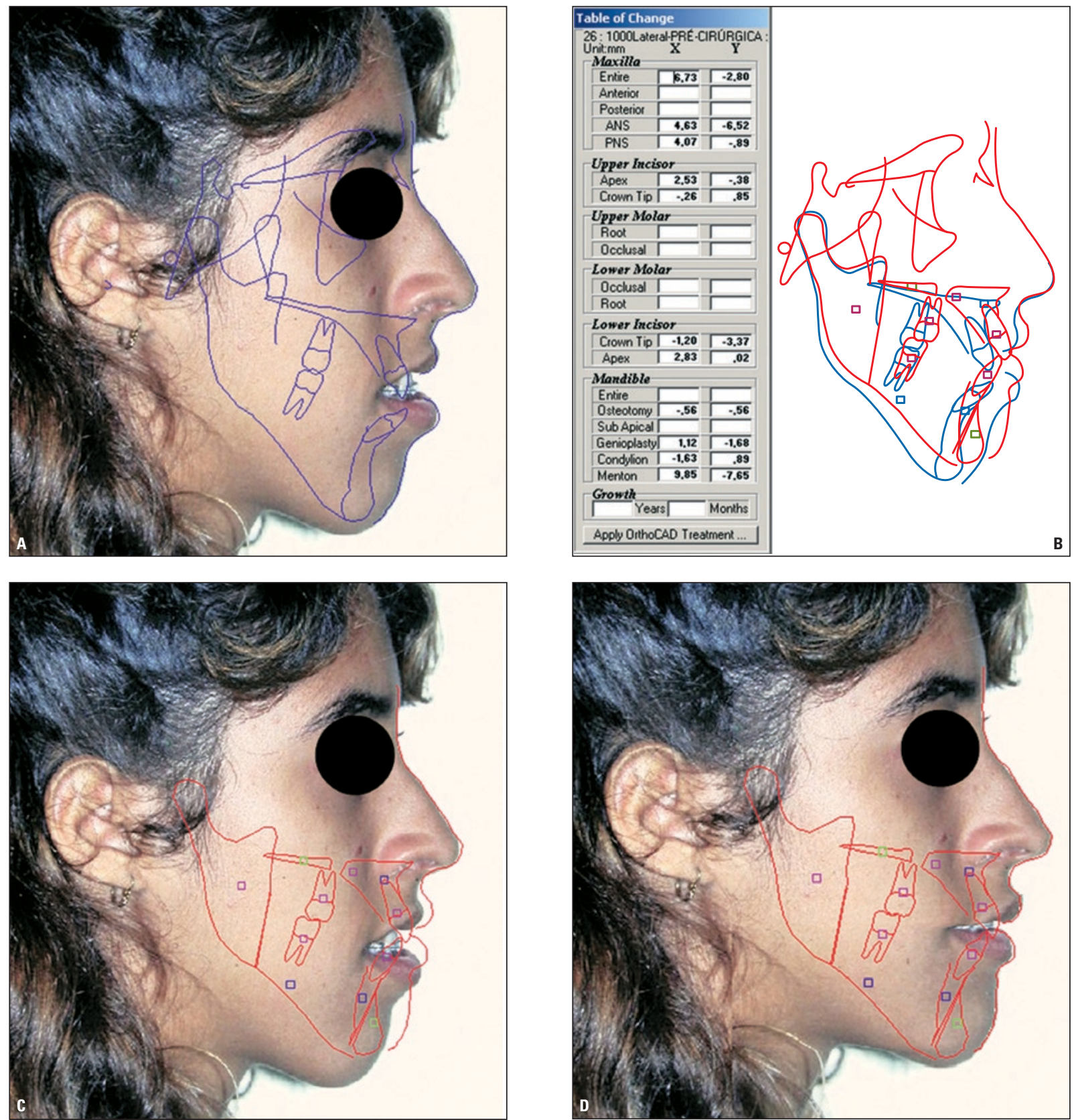

FIGURA 1 - Tela de tratamento: A) traçado pré-cirúrgico sobre a imagem pré-cirúrgica; B) movimentação das estruturas esqueléticas do traçado pré-cirúrgico (azul) construindo o traçado predictivo (vermelho) - a tabela mostra a magnitude das mudanças esqueléticas no plano horizontal e vertical; $\mathbf{C}$ ) traçado predictivo sobre a imagem pré-cirúrgica; $\mathbf{D})$ imagem predictiva contornada a partir do traçado predictivo.

bial (união dos pontos columela, subnasal e lábio superior) e mentolabial (pontos lábio inferior, ponto B' e pogônio mole). Calculou-se a diferença entre o valor em graus dos ângulos predictivos e finais, onde valores negativos indicariam ângulos predictivos mais agudos.
Para a análise subjetiva, foram apresentadas as imagens para avaliação a 20 ortodontistas (Fig. 3). Através de um questionário composto por escalas de $100 \mathrm{~mm}$, estes julgaram o grau de semelhança estética entre cinco regiões dos perfis predictivo computadorizado e final: perfil total, 
nariz, lábio superior, lábio inferior e mento. A medição das marcações nas retas, com precisão de $1 \mathrm{~mm}$, gerou notas de 0 a 100, obtendo-se 640 notas para cada variável.

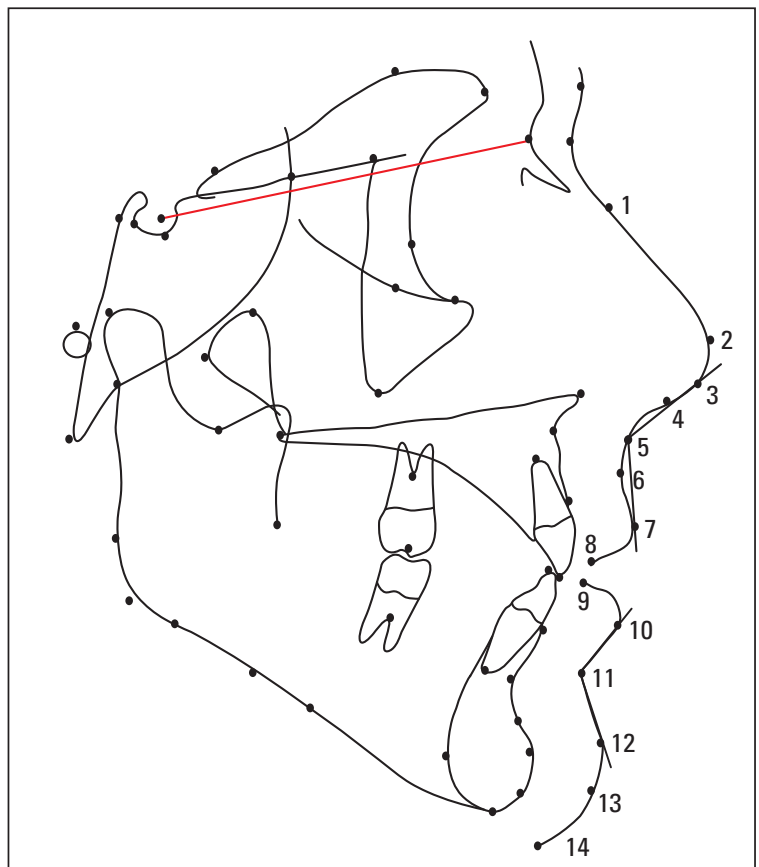

FIGURA 2 - Pontos e ângulos do perfil mole utilizados no estudo: 1) dorso nasal, 2) pronasal, 3) columela, 4) ponto " $S$ " nasal, 5) subnasal, 6) ponto $A$ ', 7) lábio superior, 8) estômio superior, 9) estômio inferior, 10) lábio inferior, 11) ponto $\left.B^{\prime}, 12\right)$ pogônio mole, 13) gnátio mole e 14) mento mole.

\section{Análise estatística}

Para a análise do erro do método, realizou-se duas vezes a marcação dos pontos cefalométricos em dez radiografias selecionadas aleatoriamente, com intervalo de uma semana. Comparando-se 9 medidas cefalométricas angulares e 5 medidas lineares, os resultados mostraram alta correlação, com valores de $r$ próximos de $1(\mathrm{P}<0,001)$.

Foi utilizado o teste $t$ de Student para o cálculo das diferenças cefalométricas entre os pontos predictivos e finais de toda a amostra e nos grupos AP e V. Para a análise subjetiva, foi utilizado o teste de Mann-Whitney para comparar as notas dos grupos AP e V. Uma avaliação da correlação linear (coeficiente de correlação de Spearman; $\mathrm{P}<0,01$ ) entre as diferenças cefalométricas e as notas dos perfis testou se as notas aumentavam à medida que o erro cefalométrico diminuía, ou seja, se o coeficiente de correlação se aproximava de -1 .

\section{RESULTADOS}

\section{Análise cefalométrica}

As tabelas 1, 2 e 3 exibem os resultados das diferenças cefalométricas em milímetros entre os pontos do perfil predictivo e final e em graus entre os ângulos nasolabial e mentolabial, para toda
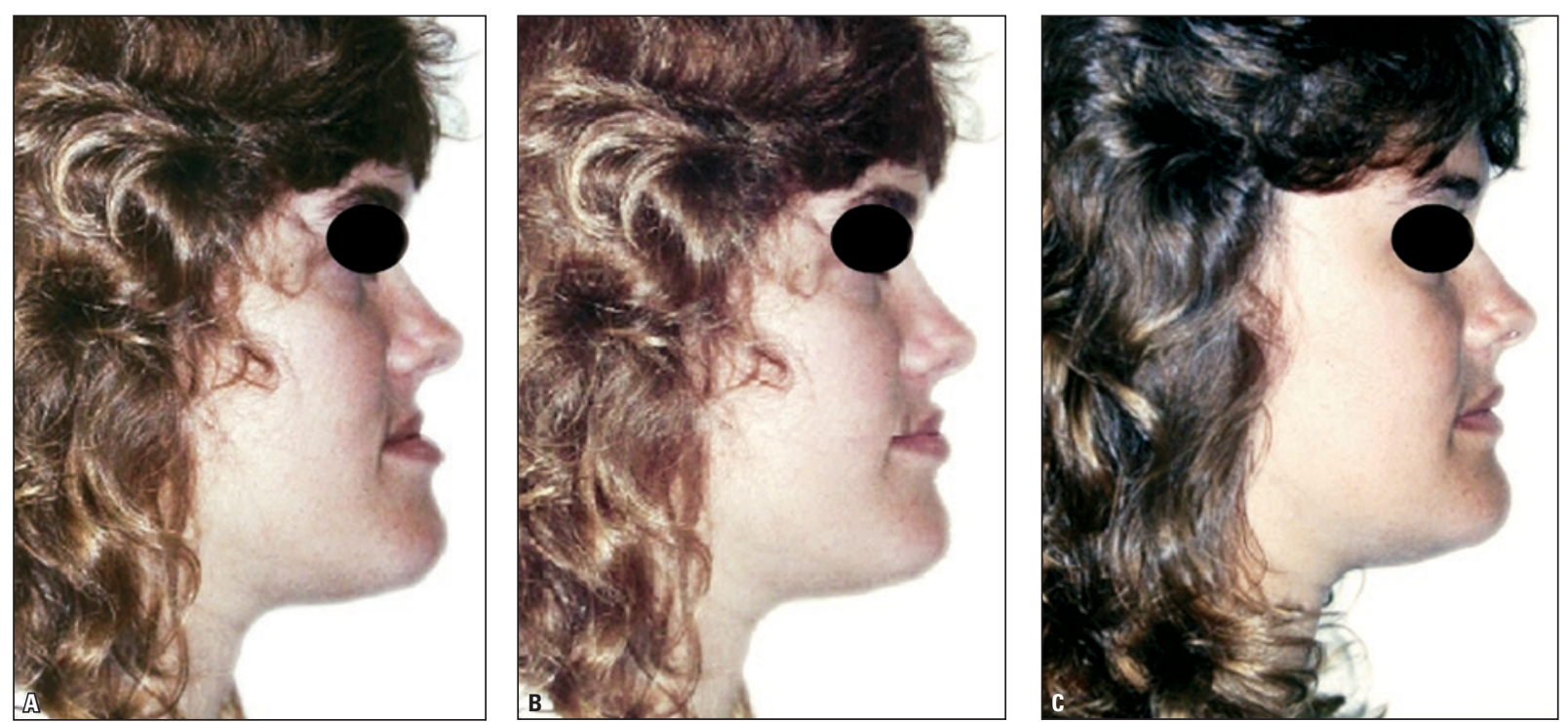

FIGURA 3 - Exemplo de imagem utilizada para comparação entre o perfil predictivo e final de um paciente da amostra. Os avaliadores julgaram o grau de semelhança entre as imagens $\mathbf{3 B}$ e $\mathbf{3 C}$. A) Perfil pré-cirúrgico; B) perfil predictivo computadorizado e C) perfil final pós-cirúrgico. 
Tabela 1 - Amostra total ( $\mathrm{n}=32$ ): médias, desvios-padrão (d.p.), valores mínimo, máximo e de P para as diferenças cefalométricas horizontais, verticais e angulares entre os pontos do perfil predictivo e final.

\begin{tabular}{|c|c|c|c|c|c|c|}
\hline \multicolumn{2}{|c|}{ ponto / ângulo } & média & d.p. & mínimo & máximo & $\mathbf{P}$ \\
\hline \multirow{14}{*}{$\begin{array}{c}\text { eixo horizontal } \\
\text { (X) }\end{array}$} & dorso nasal & $-0,2297$ & 1,6718 & $-2,65$ & 3,47 & 0,443 \\
\hline & pronasal & $-0,2634$ & 1,0398 & $-2,91$ & 1,59 & 0,162 \\
\hline & columela & $-0,5063$ & 1,2955 & $-2,93$ & 1,86 & $0,035^{*}$ \\
\hline & ponto "S" nasal & $-0,9175$ & 1,8135 & $-3,70$ & 3,18 & $0,007^{* *}$ \\
\hline & subnasal & $-0,5937$ & 1,4709 & $-3,44$ & 3,17 & $0,029 *$ \\
\hline & ponto $A^{\prime}$ & $-0,2413$ & 1,6797 & $-4,23$ & 2,12 & 0,423 \\
\hline & lábio superior & 0,2341 & 1,8166 & $-3,17$ & 3,97 & 0,472 \\
\hline & estômio superior & 0,3988 & 2,0399 & $-4,23$ & 4,50 & 0,277 \\
\hline & estômio inferior & 1,6888 & 3,5368 & $-7,40$ & 7,67 & $0,011^{*}$ \\
\hline & lábio inferior & 1,2972 & 2,7821 & $-5,55$ & 6,35 & $0,013^{*}$ \\
\hline & ponto $\mathrm{B}^{\prime}$ & 0,1669 & 2,6609 & $-5,29$ & 5,82 & 0,725 \\
\hline & pogônio mole & $-0,7031$ & 2,0302 & $-6,08$ & 3,44 & 0,059 \\
\hline & gnátio mole & $-0,4683$ & 2,1481 & $-6,09$ & 5,55 & 0,242 \\
\hline & mento mole & 0,5100 & 4,6198 & $-6,62$ & 12,17 & 0,571 \\
\hline \multirow{16}{*}{$\begin{array}{l}\text { eixo vertical } \\
\text { (Y) }\end{array}$} & dorso nasal & $-0,3466$ & 2,4914 & $-5,02$ & 5,03 & 0,437 \\
\hline & pronasal & 0,6206 & 1,7344 & $-1,85$ & 6,62 & 0,052 \\
\hline & columela & 0,6697 & 1,3459 & $-1,86$ & 4,50 & $0,008^{* *}$ \\
\hline & ponto "S" nasal & 0,6197 & 1,2151 & $-2,12$ & 3,44 & $0,007^{* *}$ \\
\hline & subnasal & 0,4953 & 1,5600 & $-2,65$ & 4,76 & 0,082 \\
\hline & ponto $A^{\prime}$ & $-0,1800$ & 1,7400 & $-2,91$ & 3,44 & 0,563 \\
\hline & lábio superior & $-0,9056$ & 1,5328 & $-5,02$ & 2,11 & $0,002^{* *}$ \\
\hline & estômio superior & $-0,8853$ & 1,5745 & $-3,97$ & 1,85 & $0,003^{* *}$ \\
\hline & estômio inferior & $-1,4459$ & 3,3450 & $-11,11$ & 3,71 & $0,020^{*}$ \\
\hline & lábio inferior & $-0,8044$ & 4,1052 & $-10,59$ & 5,02 & 0,276 \\
\hline & ponto $\mathrm{B}^{\prime}$ & $-1,5722$ & 2,6947 & $-6,88$ & 2,91 & $0,002^{* *}$ \\
\hline & pogônio mole & $-0,7281$ & 2,9541 & $-6,66$ & 6,09 & 0,173 \\
\hline & gnátio mole & $-1,0777$ & 2,5614 & $-7,15$ & 3,97 & $0,029^{*}$ \\
\hline & mento mole & $-1,9096$ & 2,7827 & $-9,52$ & 5,30 & $0,001^{* *}$ \\
\hline & ângulo nasolabial & $-4,7500$ & 8,1042 & $-19,00$ & 13,00 & $0,002^{* *}$ \\
\hline & ângulo mentolabial & $-11,7813$ & 19,6711 & $-51,00$ & 35,00 & $0,002^{* *}$ \\
\hline
\end{tabular}

${ }^{*} \mathrm{P}=0,05 ; *{ }^{*} \mathrm{P}=0,01$.

a amostra, grupo AP e grupo V, respectivamente.

$\mathrm{Na}$ análise de toda a amostra, o número de pontos com diferenças estatisticamente significativas foi maior no plano vertical (8) do que no plano horizontal (5). No grupo AP, o número de pontos com diferenças significativas foi igual nos dois planos (4). No grupo V, o número de pontos com diferenças significativas foi maior no vertical (5) do que no horizontal (3).

$\mathrm{Na}$ análise angular, foram encontradas diferenças estatisticamente significantes para o ângulo nasolabial e mentolabial na amostra total e no grupo V. Entretanto, de acordo com os valores negativos, nas três situações os ângulos predictivos se apresentaram mais agudos que seus correspondentes finais. 
Tabela 2 - Grupo AP ( $n=15)$ : médias, desvios-padrão (d.p.) e valores de P para as diferenças cefalométricas horizontais, verticais e angulares entre os pontos do perfil predictivo e final.

\begin{tabular}{|c|c|c|c|c|}
\hline \multicolumn{2}{|c|}{ ponto / ângulo } & média & d.p. & $\mathbf{P}$ \\
\hline \multirow{14}{*}{$\begin{array}{l}\text { eixo horizontal } \\
\text { (X) }\end{array}$} & dorso nasal & $-0,6720$ & 1,1436 & $0,039 *$ \\
\hline & pronasal & $-0,1607$ & 1,0405 & 0,559 \\
\hline & columela & $-0,3013$ & 1,3638 & 0,407 \\
\hline & ponto "S" nasal & $-0,5120$ & 2,0101 & 0,341 \\
\hline & subnasal & 0,2160 & 1,2130 & 0,502 \\
\hline & ponto $A^{\prime}$ & 0,1940 & 1,2737 & 0,565 \\
\hline & lábio superior & 0,6700 & 1,5876 & 0,124 \\
\hline & estômio superior & 0,8847 & 1,8753 & 0,089 \\
\hline & estômio inferior & 2,7013 & 2,7880 & $0,002^{* *}$ \\
\hline & lábio inferior & 2,0800 & 1,9652 & $0,001^{* *}$ \\
\hline & ponto $\mathrm{B}^{\prime}$ & $-0,2980$ & 2,5457 & 0,657 \\
\hline & pogônio mole & $-1,1827$ & 1,9550 & $0,034^{*}$ \\
\hline & gnátio mole & $-0,5092$ & 1,6056 & 0,275 \\
\hline & mento mole & $-0,7200$ & 3,7295 & 0,536 \\
\hline \multirow{16}{*}{$\begin{array}{l}\text { eixo vertical } \\
\text { (Y) }\end{array}$} & dorso nasal & $-0,3167$ & 1,7777 & 0,502 \\
\hline & pronasal & 0,1420 & 1,0444 & 0,607 \\
\hline & columela & 0,0886 & 1,1782 & 0,775 \\
\hline & ponto "S" nasal & 0,3000 & 1,0061 & 0,268 \\
\hline & subnasal & $-0,1240$ & 1,1651 & 0,686 \\
\hline & ponto $\mathrm{A}^{\prime}$ & $-1,0233$ & 1,3334 & $0,010^{*}$ \\
\hline & lábio superior & $-1,5693$ & 1,5480 & $0,002^{* *}$ \\
\hline & estômio superior & $-1,3040$ & 1,5337 & $0,005^{* *}$ \\
\hline & estômio inferior & $-1,8880$ & 3,8497 & 0,078 \\
\hline & lábio inferior & $-1,2920$ & 4,4573 & 0,280 \\
\hline & ponto $\mathrm{B}^{\prime}$ & $-1,1660$ & 2,5043 & 0,093 \\
\hline & pogônio mole & $-0,8680$ & 2,6740 & 0,229 \\
\hline & gnátio mole & $-1,2015$ & 2,9287 & 0,165 \\
\hline & mento mole & $-2,0191$ & 2,4505 & $0,021^{*}$ \\
\hline & ângulo nasolabial & $-3,4000$ & 8,6998 & 0,152 \\
\hline & ângulo mentolabial & $-9,6667$ & 18,9762 & 0,069 \\
\hline
\end{tabular}

${ }^{*} \mathrm{P}=0,05 ;{ }^{* * P}=0,01$.

A tabela 4 exibe uma distribuição de freqüências das diferenças cefalométricas, onde a maior parte dos erros foi menor que $2 \mathrm{~mm}$. Contudo, na categoria acima de $3 \mathrm{~mm}$ não foi estabelecido um limite máximo e alguns casos discrepantes apresentaram valores elevados, como expresso na tabela 1. Destacam-se situações bem distintas, como na comparação entre os pontos pro- nasal e estômio inferior no plano horizontal. No primeiro, 96,9\% dos casos (31 pacientes) exibiram diferenças de até $2 \mathrm{~mm}$ e em nenhum caso foram maiores que $3 \mathrm{~mm}$, enquanto, no segundo, $65,7 \%$ dos casos (21 pacientes) exibiram diferenças maiores que $2 \mathrm{~mm}, 56,3 \%$ (18 pacientes) maiores que $3 \mathrm{~mm}$ e em nenhum caso foram menores que $1 \mathrm{~mm}$. 
Tabela 3 - Grupo V ( $n=17)$ : médias, desvios-padrão (d.p.) e valores de $P$ para as diferenças cefalométricas horizontais, verticais e angulares entre os pontos do perfil predictivo e final.

\begin{tabular}{|c|c|c|c|c|}
\hline \multicolumn{2}{|c|}{ ponto / ângulo } & média & d.p. & $\mathbf{P}$ \\
\hline \multirow{14}{*}{$\begin{array}{l}\text { eixo horizontal } \\
(X)\end{array}$} & dorso nasal & 0,1606 & 1,9813 & 0,743 \\
\hline & pronasal & $-0,3541$ & 1,0626 & 0,188 \\
\hline & columela & $-0,6871$ & 1,2451 & $0,037^{*}$ \\
\hline & ponto "S" nasal & $-1,2753$ & 1,5958 & $0,005^{* *}$ \\
\hline & subnasal & $-1,3082$ & 1,3217 & $0,001^{* *}$ \\
\hline & ponto $A^{\prime}$ & $-0,6253$ & 1,9268 & 0,200 \\
\hline & lábio superior & $-0,1506$ & 1,9629 & 0,756 \\
\hline & estômio superior & $-0,0300$ & 2,1374 & 0,955 \\
\hline & estômio inferior & 0,7953 & 3,9530 & 0,419 \\
\hline & lábio inferior & 0,6065 & 3,2459 & 0,452 \\
\hline & ponto $B^{\prime}$ & 0,5771 & 2,7687 & 0,403 \\
\hline & pogônio mole & $-0,2800$ & 2,0581 & 0,583 \\
\hline & gnátio mole & $-0,4371$ & 2,5353 & 0,487 \\
\hline & mento mole & 1,3556 & 5,0842 & 0,303 \\
\hline \multirow{16}{*}{$\begin{array}{l}\text { eixo vertical } \\
\text { (Y) }\end{array}$} & dorso nasal & $-0,3729$ & 3,0429 & 0,620 \\
\hline & pronasal & 1,0429 & 2,1142 & 0,059 \\
\hline & columela & 1,1824 & 1,3035 & $0,002^{* *}$ \\
\hline & ponto "S" nasal & 0,9018 & 1,3396 & $0,014^{*}$ \\
\hline & subnasal & 1,0418 & 1,6882 & $0,022^{*}$ \\
\hline & ponto $A^{\prime}$ & 0,5641 & 1,7479 & 0,202 \\
\hline & lábio superior & $-0,3200$ & 1,2954 & 0,324 \\
\hline & estômio superior & $-0,5159$ & 1,5607 & 0,192 \\
\hline & estômio inferior & $-1,0559$ & 2,8925 & 0,152 \\
\hline & lábio inferior & $-0,3741$ & 3,8532 & 0,694 \\
\hline & ponto $\mathrm{B}^{\prime}$ & $-1,9306$ & 2,8793 & $0,014^{*}$ \\
\hline & pogônio mole & $-0,6047$ & 3,2583 & 0,455 \\
\hline & gnátio mole & $-0,9829$ & 2,3316 & 0,101 \\
\hline & mento mole & $-1,8344$ & 3,0666 & $0,030^{*}$ \\
\hline & ângulo nasolabial & $-5,9412$ & 7,6032 & $0,005^{* *}$ \\
\hline & ângulo mentolabial & $-13,6471$ & 20,6578 & $0,015^{*}$ \\
\hline
\end{tabular}

${ }^{*} \mathrm{P}=0,05 ;{ }^{* *} \mathrm{P}=0,01$.

\section{Análise subjetiva}

A tabela 5 exibe os resultados das notas de cada região, para toda a amostra. A variável de maior nota média foi o nariz, com 75,42. O lábio inferior foi a região do perfil predictivo que menor semelhança apresentou em relação à imagem final, com uma nota média de 56,00. As demais variáveis (mento, perfil total e lábio superior) apresentaram resultados bem semelhantes, 61,92; 60,35 e 60,03, respectivamente. Nota-se que o perfil total resumiu a avaliação de todas as outras, obtendo uma nota média.

A tabela 6 apresenta um comportamento dos grupossemelhante ao da amostra total.NogrupoAP, o nariz foi a variável de maior nota média $(74,37)$, o lábio inferior a de menor nota média $(55,39)$ 
Tabela 4 - Distribuição de freqüências (categorização) das diferenças cefalométricas entre os traçados predictivo e final para a amostra total $(n=32)$ : frequência de pacientes (f) e porcentagem (\%) para cada variação.

\begin{tabular}{|c|c|c|c|c|c|c|c|c|c|}
\hline & \multirow{2}{*}{ ponto } & \multicolumn{2}{|c|}{$<1 \mathrm{~mm}$} & \multicolumn{2}{|c|}{1 - $2 \mathrm{~mm}$} & \multicolumn{2}{|c|}{$2-3 m m$} & \multicolumn{2}{|c|}{$>3 \mathrm{~mm}$} \\
\hline & & $f$ & $\%$ & $f$ & $\%$ & $f$ & $\%$ & f & $\%$ \\
\hline \multirow{14}{*}{$\begin{array}{c}\text { eixo } \\
\text { horizontal } \\
\text { (X) }\end{array}$} & dorso nasal & 12 & 37,5 & 12 & 37,5 & 6 & 18,8 & 2 & 6,3 \\
\hline & pronasal & 17 & 53,1 & 14 & 43,8 & 1 & 3,1 & - & - \\
\hline & columela & 14 & 43,8 & 14 & 43,8 & 4 & 12,5 & - & - \\
\hline & ponto "S" nasal & 8 & 25 & 10 & 31,3 & 11 & 34,4 & 3 & 9,4 \\
\hline & subnasal & 17 & 53,1 & 8 & 25 & 3 & 9,4 & 4 & 12,5 \\
\hline & ponto $A^{\prime}$ & 11 & 34,4 & 13 & 40,6 & 7 & 21,9 & 1 & 3,1 \\
\hline & lábio superior & 10 & 31,3 & 13 & 40,6 & 6 & 18,8 & 3 & 9,4 \\
\hline & estômio superior & 12 & 37,5 & 11 & 34,4 & 4 & 12,5 & 5 & 15,6 \\
\hline & estômio inferior & - & - & 11 & 34,4 & 3 & 9,4 & 18 & 56,3 \\
\hline & lábio inferior & 9 & 28,1 & 5 & 15,6 & 7 & 21,9 & 11 & 34,4 \\
\hline & ponto $\mathrm{B}^{\prime}$ & 8 & 25 & 10 & 31,3 & 5 & 15,6 & 9 & 28,1 \\
\hline & pogônio mole & 9 & 28,1 & 8 & 25 & 11 & 34,4 & 4 & 12,5 \\
\hline & gnátio mole & 9 & 28,1 & 15 & 46,9 & 3 & 9,4 & 3 & 9,4 \\
\hline & mento mole & 6 & 18,8 & 3 & 9,4 & 4 & 12,5 & 14 & 43,8 \\
\hline \multirow{14}{*}{$\begin{array}{c}\text { eixo } \\
\text { vertical } \\
\text { (Y) }\end{array}$} & dorso nasal & 4 & 12,5 & 16 & 50 & 6 & 18,8 & 6 & 18,8 \\
\hline & pronasal & 16 & 50 & 11 & 34,4 & 3 & 9,4 & 2 & 6,3 \\
\hline & columela & 17 & 53,1 & 11 & 34,4 & 3 & 9,4 & 1 & 3,1 \\
\hline & ponto "S" nasal & 13 & 40,6 & 14 & 43,8 & 4 & 12,5 & 1 & 3,1 \\
\hline & subnasal & 12 & 37,5 & 13 & 40,6 & 6 & 18,8 & 1 & 3,1 \\
\hline & ponto $A^{\prime}$ & 14 & 43,8 & 6 & 18,8 & 10 & 31,3 & 2 & 6,3 \\
\hline & lábio superior & 11 & 34,4 & 14 & 43,8 & 5 & 15,6 & 2 & 6,3 \\
\hline & estômio superior & 13 & 40,6 & 10 & 31,3 & 5 & 15,6 & 4 & 12,5 \\
\hline & estômio inferior & 9 & 28,1 & 6 & 18,8 & 5 & 15,6 & 12 & 37,5 \\
\hline & lábio inferior & 5 & 15,6 & 9 & 28,1 & 4 & 12,5 & 14 & 43,8 \\
\hline & ponto $\mathrm{B}^{\prime}$ & 5 & 15,6 & 14 & 43,8 & 4 & 12,5 & 9 & 28,1 \\
\hline & pogônio mole & 10 & 31,3 & 10 & 31,3 & 4 & 12,5 & 8 & 25 \\
\hline & gnátio mole & 9 & 28,1 & 6 & 18,8 & 10 & 31,3 & 5 & 15,6 \\
\hline & mento mole & 7 & 21,9 & 5 & 15,6 & 7 & 21,9 & 8 & 25 \\
\hline
\end{tabular}

Tabela 5 - Amostra total $(\mathrm{n}=32$ ): médias, desvios-padrão (d.p.), valores mínimo e máximo das notas dos avaliadores para cada região do perfil.

\begin{tabular}{ccccc}
\hline região do perfil & média & d.p. & mínimo & máximo \\
\hline perfil total & 60,35 & 9,6596 & 40,30 & 73,90 \\
nariz & 75,42 & 6,9801 & 57,60 & 85,15 \\
lábio superior & 60,03 & 11,1090 & 39,30 & 78,45 \\
lábio inferior & 56,00 & 10,5822 & 36,65 & 74,00 \\
mento & 61,92 & 10,9403 & 29,85 & 78,60 \\
\hline
\end{tabular}


Tabela 6 - Comparação entre os grupos AP $(n=15)$ e V $(n=17)$ : médias, desvios-padrão (d.p.), valores mínimo, máximo e de P para as notas dos avaliadores.

\begin{tabular}{|c|c|c|c|c|c|c|}
\hline região do perfil & grupo & média & d.p. & mínimo & máximo & $\mathbf{P}$ \\
\hline \multirow[t]{2}{*}{ perfil total } & AP & 60,39 & 10,6169 & 40,30 & 72,80 & 0,777 \\
\hline & V & 60,31 & 9,0637 & 44,95 & 73,90 & \\
\hline \multirow[t]{2}{*}{ nariz } & AP & 74,37 & 7,7533 & 57,60 & 84,95 & 0,439 \\
\hline & V & 76,35 & 6,3111 & 58,85 & 85,15 & \\
\hline \multirow[t]{2}{*}{ lábio superior } & AP & 59,65 & 12,6778 & 39,30 & 78,45 & 1,000 \\
\hline & V & 60,36 & 9,9106 & 39,75 & 76,80 & \\
\hline \multirow[t]{2}{*}{ lábio inferior } & AP & 55,39 & 12,5632 & 36,65 & 74,00 & 0,955 \\
\hline & V & 56,53 & 8,8435 & 42,80 & 73,40 & \\
\hline \multirow[t]{2}{*}{ mento } & AP & 60,80 & 12,7487 & 29,85 & 76,35 & 0,970 \\
\hline & V & 62,91 & 9,3523 & 44,85 & 78,60 & \\
\hline
\end{tabular}

${ }^{*} \mathrm{P}=0,05 ;{ }^{* *} \mathrm{P}=0,01$.

e as demais mostraram valores semelhantes, 60,80 ; 60,39 e 59,65 para o mento, perfil total e lábio superior, respectivamente. No grupo $\mathrm{V}$, observou-se comportamento semelhante: 76,35 para o nariz, 56,53 para o lábio inferior e 62,91; 60,36 e 60,31 para o mento, lábio superior e perfil total, respectivamente. Não foram encontradas diferenças significativas na comparação entre os grupos em nenhuma das regiões avaliadas.

\section{Correlação}

Para a avaliação da correlação linear foram utilizados os valores absolutos das diferenças cefalométricas, sem levar em consideração o sinal positivo ou negativo, considerando-se a quantidade do erro nos pontos predictivos, e não a direção. Foram agrupadas duplas de medidas, relacionando as regiões do perfil aos pontos cefalométricos correspondentes. Os valores encontrados foram quase todos não significativos $(\mathrm{P}<0,01)$. Houve diferença estatisticamente significante apenas na correlação entre a região do lábio inferior e o ponto lábio inferior $(\mathrm{P}$ $<0,01)$ e entre a região perfil total e o ponto lábio inferior $(\mathrm{P}<0,05)$. Entretanto, no primeiro caso o valor de $r$ foi de 0,481 e no segundo foi de 0,355 , demonstrando baixa correlação entre as variáveis. Esta tendência foi confirmada em todos os casos, onde o valor de r oscilou entre -0,320 e +0,481.

\section{DISCUSSÃO}

Observou-se variabilidade no posicionamento de vários pontos cefalométricos na comparação entre os traçados predictivos e finais, tanto para a amostra total quanto por grupos, onde mais de $60 \%$ dos erros foram menores que $2 \mathrm{~mm}$, e em $17 \%$ as diferenças excederam o limite de $3 \mathrm{~mm}$. Maior precisão foi encontrada em outros trabalhos, como uma diferença menor que $1 \mathrm{~mm}$ para $50 \%$ e menor que $2 \mathrm{~mm}$ para $78 \%$ das medidas ${ }^{2}$ e uma discrepância maior que $2 \mathrm{~mm}$ em apenas $20 \%$ dos $\operatorname{casos}^{21}$.

O número de pontos com diferenças estatisticamente significantes foi, de forma geral, maior nas medidas verticais do que nas horizontais, concordando com vários trabalhos $3,6,8,9,24$. Os programas OTP e PPP, por exemplo, apresentaram duas vezes mais erros no plano vertical em relação ao plano horizontal ${ }^{18}$.

A região do lábio inferior é citada freqüentemente na literatura como a de pior predição $\mathrm{O}^{2,10,21,23}$, encontrando-se ali as maiores diferenças cefalométricas, com uma média de $1,12 \mathrm{~mm}$ a $1,4 \mathrm{~mm}$. No presente estudo, a média das diferenças para o ponto lábio inferior foi de $1,29 \mathrm{~mm}$ no sentido horizontal e de $0,80 \mathrm{~mm}$ no sentido vertical, para a amostra total. $\mathrm{O}$ estômio inferior, no sentido horizontal e vertical $(1,68 \mathrm{~mm}$ e $1,44 \mathrm{~mm}$, res- 
pectivamente) e o ponto B', no sentido vertical $(1,57 \mathrm{~mm})$, e pontos do lábio inferior também apresentaram médias desta magnitude. No grupo AP, os erros cefaloméricos chegaram a $2,08 \mathrm{~mm}$ para o ponto lábio inferior e $2,70 \mathrm{~mm}$ para o estômio inferior, ambos no sentido horizontal. Entretanto, pontos em outras regiões mostraram valores próximos, como o ponto $S$ nasal $(0,91 \mathrm{~mm})$, no sentido horizontal, e os pontos lábio superior $(0,90 \mathrm{~mm})$, estômio superior $(0,88 \mathrm{~mm})$, gnátio' $(1,07 \mathrm{~mm})$ e mentoniano' $(1,90 \mathrm{~mm})$, no vertical.

Observa-se na literatura ${ }^{3,7,18,24}$ que, assim como o Vistadent neste trabalho, os programas de simulação computadorizada raramente simulam com sucesso a acomodação do lábio inferior após impacção maxilar ou avanço mandibular, onde o lábio inferior que se apresentava contido sob os incisivos superiores é liberado. O lábio inferior está sujeito a variadas influências, sendo difícil apontar exatamente como este irá se posicionar após os movimentos esqueléticos ${ }^{23}$.

$\mathrm{Na}$ análise angular, a tendência de serem originados ângulos predictivos mais agudos se repetiu nas três situações (amostra total, grupo AP e $\mathrm{V}$ ), o que pode demonstrar uma tendência à compressão da imagem predictiva na utilização do programa testado. Isto não dependeu diretamente da presença de rotação mandibular, parecendo uma falha constante do programa. Pode-se sugerir que a notória imprecisão nos lábios poderia gerar posições mais evertidas na predição, o que levaria a uma redução nos valores dos ângulos nasolabial e mentolabial.

Os resultados da análise subjetiva sugerem que houve, em comparação com outros trabalhos, uma melhor avaliação por parte dos profissionais no presente estudo. Os resultados de um trabalho testando o programa PPP também exibiram o nariz $(61,53)$ como a variável de melhor nota média e o lábio inferior $(42,63)$ como a região de pior predição, mas com valores inferiores aos 75,42 e 56,00, respectivamente, do Vistadent ${ }^{13}$. As melhores notas atribuídas à re- gião nasal nestes dois estudos podem ter resultado da participação de indivíduos submetidos a cirurgias mandibulares isoladas, o que não resultaria em alterações no nariz. Uma avaliação dos programas PPP e OTP exibiu uma nota média total de 55,00 , onde o lábio inferior obteve a pior avaliação $(51,00)$, enquanto as regiões mais bem avaliadas foram o lábio superior, o mento e a região cervical $(64,00)^{23}$. Médias mais baixas para o lábio inferior foram encontradas testando-se tanto o PPP $(52,9)$ quanto o OTP $(52,5)$, e mais altas para o ângulo nasolabial, que recebeu 70,6 e 62,5 , respectivamente ${ }^{18}$

A comparação dos grupos AP e V na análise subjetiva não resultou em diferença estatisticamente significante, mostrando que o componente vertical não foi determinante na qualidade das imagens predictivas, segundo a percepção dos avaliadores. Desta forma, pode-se sugerir que o programa avaliado não apresentou restrições à execução de predições em casos de impacção de maxila seguida de giro mandibular. Entretanto, no único caso de reposicionamento inferior de maxila obteve-se uma imagem predictiva bastante deficiente, com distorção do lábio superior, quando o programa expandiu a imagem para aumentar o terço médio da face.

A baixa correlação encontrada sugere que as diferenças cefalométricas não influenciaram diretamente a avaliação das imagens pelos ortodontistas. Em um trabalho com a maioria das diferenças cefalométricas abaixo de $1 \mathrm{~mm}$, foram encontrados na avaliação subjetiva conceitos apenas regulares a bons, e este fato foi atribuído à baixa qualidade visual das imagens ${ }^{23}$. Em outro estudo, apesar de resultados relativamente ruins nas predições cefalométricas, observou-se avaliações de regulares a boas na análise subjetiva, sugerindo que erros de $1 \mathrm{~mm}$ a $2 \mathrm{~mm}$ foram aceitáveis clinicamente ${ }^{8}$.

$\mathrm{Na}$ verdade, a obtenção de um traçado predictivo correto pode não garantir uma imagem fotográfica com detalhes satisfatórios no perfil, já 
que outros fatores parecem estar envolvidos neste processo. Falhas inerentes ao programa, como no acoplamento do traçado à fotografia ou no recorte da imagem predictiva promovendo um contorno pouco nítido e artificial, podem influenciar negativamente o resultado. Assim como variações individuais, já que diferenças em milímetros podem ter significado distinto dependendo da região onde ocorrem e da complexidade do caso em questão. A construção da imagem parece ser diferente em casos de avanço, onde a mandíbula tem que ser esticada ou deslizada para frente até atingir a linha do perfil predictivo, ou recuo mandibular, onde esta tem que ser encurtada ou recortada, e tais diferenças operacionais podem resultar em variações adicionais. Além disso, por mais fidedigna que a imagem predictiva seja ao contorno do traçado predictivo, esta continuará apresentando algumas características da imagem pré-cirúrgica, da qual foi originada. E esta pode diferir da imagem final em cor da pele, postura dos lábios, corte do cabelo, por causa de diferenças de peso ou até pelo próprio envelhecimento do paciente.

Alguns recursos de melhorias de imagens estão disponíveis nos programas, mas não foram utilizados neste estudo, evitando a presença de variáveis adicionais. Entretanto, tais recursos de retoque tiveram pouca influência no julgamento da qualidade das imagens em outro estudo ${ }^{22}$. $\mathrm{Na}$ prática clínica, entretanto, o profissional tem a opção de realizar alterações no contorno das imagens predictivas, baseando-se em sua experiência profissional e superando, de certa forma, algumas deficiências do programa.

\section{CONCLUSÕES}

1) Os pontos predictivos do perfil mole apresentaram variabilidade em relação ao perfil final, sendo que mais de $60 \%$ dos erros foram menores que $2 \mathrm{~mm}$ e $17 \%$ excederam $3 \mathrm{~mm}$. As diferenças estatisticamente significantes entre os pontos foram mais freqüentes no sentido vertical. Os ângulos nasolabial e mentolabial predictivos apre- sentaram-se mais agudos que nos traçados finais.

2) A avaliação da semelhança entre as imagens predictivas computadorizadas e finais pelos ortodontistas exibiu notas médias superiores à literatura, variando de 56,00 para o lábio inferior a 75,42 para o nariz. A qualidade das imagens predictivas não apresentou diferenças significantes em relação às alterações verticais.

3) A baixa correlação entre as análises cefalométrica e subjetiva indicou que uma não influenciou diretamente a outra, sugerindo que outros fatores, como falhas inerentes aos procedimentos digitais do programa, características individuais dos pacientes e problemas de padronização fotográfica estiveram envolvidos no processo de predição computadorizada.

4) Em comparação com a performance de outros sistemas de simulação computadorizada, o programa testado pode ser considerado útil na prática clínica ortodôntica e cirúrgica. Entretanto, baseando-se em algumas limitações observadas, recomenda-se cautela no planejamento e apresentação do caso, sendo que algumas predições podem exigir melhorias com as ferramentas de ajuste disponíveis no programa.

\section{AGRADECIMENTOS}

Aos professores e residentes do serviço de Cirurgia Bucomaxilofacial do Hospital Universitário Pedro Ernesto (HUPE/UERJ) pela parceria no tratamento e na seleção dos pacientes da amostra.

\footnotetext{
Endereço para correspondência

Alexandre Trindade Simões da Motta

Rua Desembargador João Claudino de Oliveira e Cruz, 50/1507

CEP: 22.793-071 - Barra da Tijuca - Rio de Janeiro / RJ

E-mail: alemotta@rjnet.com.br
} 


\title{
Prediction of soft-tissue profile by video imaging in orthognathic surgery: cephalometric accuracy and orthodontists' judgement
}

\begin{abstract}
Aim: To verify the accuracy of a video imaging software on the soft tissue profile prediction of patients who underwent different types of orthognathic surgery. Methods: Presurgical and posttreatment lateral cephalograms and photographs of 32 patients were used. Profile predictions were obtained from hard tissue manipulation on the presurgical tracings. Prediction evaluation was applied to the total sample and to subgroups with maxillary impaction or downgraft $(V)$ or without surgeries in the vertical plane (AP). Points of prediction's soft tissue line were compared with those of the posttreatment tracing. Prediction and posttreatment profile images were subjectively compared by 20 orthodontists. Five regions (overall profile, nose, upper lip, lower lip and chin) were graded from 0 to 100 with a visual analog scale. Results and Conclusions: Soft-tissue profile points showed location variability, with more than $60 \%$ of the errors up to $2 \mathrm{~mm}$ and $17 \%$ greater than $3 \mathrm{~mm}$. Statistically significant differences in the cephalometric analysis were more frequently observed on the vertical plane. Nasolabial and mentolabial prediction angles were more acute than those of the posttreatment tracings. The aesthetic analysis showed greater mean values in comparison with other studies, varying from 56.00 for the lower lip to $\mathbf{7 5 . 4 2}$ for the nose. Prediction images precision showed no significant difference between cases with or without vertical changes. This program can be considered useful in orthodontic and surgical clinical practice. However, based on some observed limitations, the authors recommend caution in treatment planning and case presentation, and some predictions may require improvement with enhancement tools.
\end{abstract}

Key words: Video imaging. Profile prediction. Orthognathic surgery.

\section{REFERÊNCIAS}

1. CARTER, A. C.; LARSON, B. E.; GUENTHNER, A. T. Accuracy of video imaging in mandibular surgery. Int. J. Adult Orthod. Orthognath. Surg., Chicago, v. 11, no. 4, p. 289-300, 1996

2. CURTIS, T. J. et al. Accuracy of a computerized method of predicting soft-tissue changes from orthognatic surgery. J. Clin. Orthod., Boulder, v. 34, no. 9, p. 524-530, Sept. 2000

3. EALES, E. A. et al. The accuracy of computerized prediction of the soft tissue profile: a study of 25 patients treated by means of the Le Fort I osteotomy. Int. J. Adult Orthod. Orthognath. Surg., Chicago, v. 9, no. 2, p. 141-152, 1994

4. GIANGRECO, T. A. et al. Subjective evaluation of profile prediction using video imaging. Int. J. Adult Orthod. Orthognath. Surg. Chicago, v. 10, no. 3, p. 211-216, 1995.

5. GUESS, M. B.; SOLZER, W. V. Computer treatment estimates in Orthodontics and Orthognatic Surgery. J. Clin. Orthod., Boulder, v. 23, no. 4, p. 262-268, Apr. 1989

6. HING, N. R. The accuracy of computer generated tracings. Int. J. Oral Maxillofac. Surg., Copenhagen, v. 18, no. 3, p. 148-151, 1989.

7. JENSEN, A. C.; SINCLAIR, P. M.; WOLFORD, L. M. Soft-tissue changes associated with double jaw surgery. Am. J. Orthod. Dentofacial Orthop., St. Louis, v. 101, no. 3, p. 266-275, Mar. 1992.

8. KAZANDJIAN, S. et al. Accuracy of video imaging for predicting the soft tissue profile after mandibular set-back surgery. Am. J. Orthod. Dentofacial Orthop., St. Louis, v. 115, no. 4, p. 382389, Apr. 1999.

9. KONSTIANTOS, K. A. O'REILLY, M. T.: CLOSE, J. The validity of the prediction of soft tissue profile changes after Le Fort I osteotomy using the dentofacial planner (computer software). Am. J. Orthod. Dentofacial Orthop., St. Louis, v. 105, no. 3 , p. 241-249, Mar. 1994.

10. LU, C. H., KO, E. W.; HUANG, C. S. The accuracy of video imaging prediction in soft tissue outcome after bimaxillary orthognatic surgery. J. Oral Maxillofac. Surg., Philadelphia, v. 61, no. 3, p. 333-342, 2003.

11. MEDEIROS, P. J. D.; MEDEIROS, P. P. Cirurgia ortognática para o ortodontista. 2. ed. São Paulo: Ed. Santos, 2004.

12. MOTTA, A. T. S. A acuidade do video imaging na predição das mudanças no perfil de pacientes submetidos à cirurgia ortognática. 2001. Trabalho de Conclusão de Curso (Especialização)-Faculdade de Odontologia, Universidade do Estado do Rio de Janeiro, Rio de Janeiro, 2001

13. MOTTA, A. T. S. et al. A acuidade do video imaging na predição das mudanças ocorridas no perfil de pacientes submetidos à cirurgia ortognática. R. Dental Press Ortodon. Ortop. Facial Maringá, v. 9, n.1, p. 103-112, jan./fev. 2004.

14. MOTTA, A. T. S. Avaliação estética e cefalométrica da predição do perfil facial em casos ortocirúrgicos por um programa de simulação computadorizada. 2004. Dissertação (Mestrado)-Faculdade de Odontologia, Universidade do Estado do Rio de Janeiro, Rio de Janeiro, 2004.

15. MOTTA, A. T. S. et al. Orthodontic and surgical treatment of an ankylosed temporomandibular joint case. Am. J. Orthod. Dentofacial Orthop., St. Louis, v. 131, no. 6, p. 785-796, June 2007.

16. PHILLIPS, C. P.; HILL, B. J.; CANNAC, C. The influence of video imaging on patients' perceptions and expectations. Angle Orthod., Appleton, v. 65, no. 4, p. 263-270, 1995.

17. ROMANI, K. L. et al. Evaluation of horizontal and vertical differences in facial profiles by orthodontists and lay people. Angle Orthod., Appleton, v. 63, no. 3, p. 175-182, 1993

18. SAMESHIMA, G. T. et al. Predicting soft tissue changes in maxillary impaction surgery: a comparison of two video imaging systems. Angle Orthod., Appleton, v. 67, no. 5, p. 347-354, 1997.

19. SARVER, D. M.; JOHNSTON, M. W.; MATUKAS, V. J. Video imaging for planning and counseling in orthognatic surgery. J. Oral Maxillofac. Surg., Philadelphia, v. 46, no. 11, p. 939-945, 1988

20. SARVER, D. M. Videoimaging: the pros and cons. Angle Orthod. Appleton, v. 63, no. 3, p. 167-170, 1993.

21. SINCLAIR, P. M. et al. The accuracy of video imaging in orthognatic surgery. Am. J. Orthod. Dentofacial Orthop., St. Louis, v. 107 , no. 2 , p. 177-185, Feb. 1995

22. SMITH, J. D.; THOMAS, P. M.; PROFFIT, W. R. A comparison of current prediction imaging programs. Am. J. Orthod. Dentofacial Orthop., St. Louis, v. 125, no. 5, p. 527-536, May, 2004

23. SYLIANGCO, S. T. et al. Predicting soft tissue changes in mandibular advancement surgery: a comparison of two video imaging systems. Angle Orthod., Appleton, v. 67, no. 5, p. 337-346, 1997.

24. UPTON, P. M. et al. Evaluation of video imaging prediction in combined maxillary and mandibular orthognatic surgery. Am. J. Orthod. Dentofacial Orthop., St. Louis, v. 112, no. 6, p. 656665, Dec. 1997. 